University of Nebraska - Lincoln

DigitalCommons@University of Nebraska - Lincoln

$11-2020$

\title{
Toward the Standardization of Mesoscale Meteorological Networks
}

Christopher Fiebrich

Kevin Brinson

Rezaul Mahmood

Stuart Foster

Megan Schargorodski

See next page for additional authors

Follow this and additional works at: https://digitalcommons.unl.edu/natrespapers

Part of the Natural Resources and Conservation Commons, Natural Resources Management and Policy Commons, and the Other Environmental Sciences Commons

This Article is brought to you for free and open access by the Natural Resources, School of at DigitalCommons@University of Nebraska - Lincoln. It has been accepted for inclusion in Papers in Natural Resources by an authorized administrator of DigitalCommons@University of Nebraska - Lincoln. 


\section{Authors}

Christopher Fiebrich, Kevin Brinson, Rezaul Mahmood, Stuart Foster, Megan Schargorodski, Nathan L. Edwards, Christopher A. Redmond, Jennie R. Atkins, Jeffrey Andresen, and Xiaomao Lin 


\title{
Toward the Standardization of Mesoscale Meteorological Networks
}

\author{
Christopher A. Fiebrich, ${ }^{\text {a }}$ Kevin R. Brinson, ${ }^{\mathrm{b}}$ Rezaul Mahmood, ${ }^{\mathrm{c}}$ Stuart A. Foster,${ }^{\mathrm{d}}$ \\ Megan Schargorodski, ${ }^{\mathrm{e}}$ NATHAN L. Edwards,${ }^{\mathrm{f}}$ Christopher A. Redmond, ${ }^{\mathrm{g}}$ JenNiE R. AtKins, ${ }^{\mathrm{h}}$ \\ JeFFrey A. ANDRESEN, ${ }^{\mathrm{i}}$ AND XIAOMAo Lin ${ }^{j}$ \\ ${ }^{a}$ Oklahoma Mesonet, University of Oklahoma, Norman, Oklahoma; ${ }^{\mathrm{b}}$ Center for Environmental Monitoring and Analysis, \\ University of Delaware, Newark, Delaware; ${ }^{\mathrm{c}}$ High Plains Regional Climate Center, School of Natural Resources, University of \\ Nebraska-Lincoln, Lincoln, Nebraska; ${ }^{\mathrm{d}}$ Kentucky Climate Center, Western Kentucky University, Bowling Green, Kentucky; \\ ${ }^{\mathrm{e}}$ Kentucky Mesonet, Western Kentucky University, Bowling Green, Kentucky; ${ }^{\mathrm{f}}$ South Dakota Mesonet, South Dakota State \\ University, Brookings, South Dakota; ${ }^{\mathrm{g}}$ Kansas Mesonet, Kansas State University, Manhattan, Kansas; ${ }^{\mathrm{h}}$ Illinois State Water Survey, \\ University of Illinois at Urbana-Champaign, Champaign, Illinois, ${ }^{\mathrm{i}}$ Department of Geography, Michigan State University, \\ East Lansing, Michigan; ${ }^{j}$ Department of Agronomy, Kansas State University, Manhattan, Kansas
}

(Manuscript received 28 May 2020, in final form 1 September 2020)

\begin{abstract}
Although they share many common qualities in design and operation, mesonetworks across the United States were established independently and organically over the last several decades. In numerous instances, the unique ways each network matured and developed new protocols has led to important lessons learned. These experiences have been shared in informal ways among various network operators over the years to promote reliable operation. As existing networks begin to introduce new sensors and technologies, and as new networks come online, there is a common need for guidance on best practices. This paper aims to formally provide recommendations to improve and harmonize the various aspects of operating a "mesonet," including siting, sensors, maintenance, quality assurance, and data processing.
\end{abstract}

KEYWORDS: In situ atmospheric observations; Instrumentation/sensors; Measurements; Quality assurance/control; Sampling; Surface observations

\section{Introduction}

Over the past several decades, mesoscale networks of automated, in situ stations for weather monitoring have been developed and deployed across diverse regional settings (Mahmood et al. 2017). These networks, commonly referred to as mesonets, have originated independently, are funded at various levels and through various mechanisms, and serve a variety of constituencies and needs. While sharing commonalities, each network has unique strategic, design, and operational elements. As sensor and communications technologies evolve and the demand for weather and climate data to support decision-making grows, mesonets are expected to play an increasing role in support of weather and climate services.

Currently, there exist inconsistent functional practices and metadata reporting among mesonets. Beginning in 2016, the American Association of State Climatologists (AASC) Mesonet Committee formed subcommittees composed of mesonet operators with goals to 1) assess the current practices and capacity of U.S. mesonets and 2) identify best practices and develop guidelines for mesonets. This paper stems from a best practices guide developed by these committees (available at https://stateclimate.org/best-practices/). Guidance on metadata is based largely on the National Research Council (2009) report titled Observing Weather and Climate from the Ground Up: A Nationwide Network of Networks, as well as current practices of those mesonets that actively participate in the National Mesonet Program (https:// nationalmesonet.us).

Corresponding author: Christopher A. Fiebrich, fiebrich@ou.edu
The definition of a mesonet has evolved over the decades. Increasingly, mesonets are developing new capacities to observe the environment (e.g., boundary layer profilers, unmanned aircraft systems, atmospheric chemistry sensors). For the purposes of this paper, we define a mesonet as a network of automated, fixed, surface weather observing stations that 1) monitor environmental variables in the vertical domain between $10 \mathrm{~m}$ above and $1 \mathrm{~m}$ below ground surface (e.g., air temperature, relative humidity, rainfall, winds, solar radiation, atmospheric pressure, soil temperature, and soil moisture), 2) report data at a subhourly temporal resolution, and 3) have a spatial density on the order of one station per $1000 \mathrm{~km}^{2}$ (average spacing of approximately $30 \mathrm{~km}$ ). We further recognize that an emphasis on data quality, reliability, and completeness is vital to a mesonet's ability to effectively deliver services in near-real time and document climatic conditions over the long term. While we recognize other stakeholders of mesonet data, such as agriculture, energy, public safety, natural resource management, fire weather, and air quality, we focus here solely on the needs of the weather and climate community.

The objective of this paper is to discuss best practices for mesonets regarding functional practices and metadata reporting based on the needs of and supported by scientific research from the mesoscale weather and climate community. The discussion focuses on siting, sensors, maintenance, quality assurance, and data processing. Specific recommendations aim to improve and recognize quality and harmonize management strategies among mesonets in the United States. The recommendations herein are intended to be operational guidelines rather than standards. Standards defined by other science and 
engineering bodies were leveraged in developing our recommendations when it made sense to do so.

\section{Siting}

The quality and utility of data collected by a mesonet are fundamentally related to the proper siting of stations and associated sensors. Given the objective of collecting observations that are representative of the mesoscale environment (i.e., on the scale of 3-100 km; World Meteorological Organization 2003), efforts related to station siting should be focused on finding appropriate sites for monitoring and exposing sensors in a manner that minimizes the influence of any potential sources of microscale bias.

\section{a. Station siting}

Oftentimes for a meteorological network, the first challenge in siting a station is finding available land that is stable, secure, with appropriate access, with a willing landowner (be it private or public), with access to communications infrastructure (e.g., cellular telephone or radio coverage), and with access to power (i.e., if AC power is required; World Meteorological Organization 1993). Once a handful of potential locations are identified, the next step is to identify an optimal location. Regardless of the number of stations deployed to sample the near-surface environment across a mesonet, those stations cover only a minute subset of the potentially available monitoring locations. The intention thus is to place stations at locations that are broadly representative of the surrounding mesoscale environment. Doing so inherently demands a broad understanding of the character of the target mesoscale environment and the ability to identify sites whose representativeness is not unduly compromised by microscale influences.

Siting guidelines related to exposure of weather stations to environmental conditions have traditionally focused on site exposure in relation to an idealized landscape, broadly considered to be a flat, manicured grassy surface in an open, undeveloped area where airflow is unimpeded by obstacles (World Meteorological Organization 2014b). Recognizing this ideal, but acknowledging complexities of mesoscale environments, the footprint of a mesonet station should be a flat, or nearly flat, natural surface at least $100 \mathrm{~m}^{2}$ in area. In many, but not all areas, the natural surface cover should be grass (World Meteorological Organization 2014b). This footprint represents the physical site of the station and is the area that is maintained during regular site visits to ensure long-term site integrity (Fiebrich et al. 2006). Hence, stations not sited over natural surfaces (e.g., stations mounted on rooftops, walls, machinery, vehicles) are not recognized as being representative of mesoscale environments. While metadata that document microscale influences or deficiencies in a station's surroundings are critically important, it is perhaps even more important that a mesonet attempt to adhere to high quality siting standards when selecting station locations. Additionally, we note that that most mesonet data users will never inquire nor retrieve metadata about the stations.

No mesoscale landscape conforms to an isotropic plain. Thus, when the mesoscale environment is heterogeneous, the ability of a single station to be sited in a manner that is broadly representative of the mesoscale environment is compromised.
For instance, a gently rolling agricultural area may be sparsely populated with trees, dissected by occasional streams, and altered in places by roads, buildings, and other elements of the built environment. For some measurements, proximity to such natural or built features can have undue influence on observations, producing a microscale bias that causes those observations to be less representative of the broader mesoscale environment. Likewise, a mesoscale environment may include distinct physiographic types (i.e., ridges and valleys, coastal and inland zones, etc.), land-use types (i.e., agriculture, lowdensity development, etc.) and land-cover types (i.e., crops, pasture, forest, etc.). In such situations, a given station may be sited to be representative of a particular landscape type, with the goal of siting stations that are representative of the diversity of types present at the mesoscale. With these considerations in mind, it is important for the stations to be located to minimize undue influence of features present in the microscale environment, particularly those that are not prevalent and do not otherwise have a strong influence on the mesoscale environment. For example, a mesonet should avoid siting a station near a considerable urban influence (e.g., commercial area, industrial zone) when the representative mesoscale landscape is largely open and rural. Basara et al. (2008) documented significant temperature biases between stations located within the Oklahoma City central business district when compared with data from neighboring mesonet stations outside the city. Kumamoto et al. (2013) measured noticeable impact on air temperature measurements up to $15 \mathrm{~m}$ away from an asphalt roadway.

Additionally, a mesonet station should not be located near an isolated reservoir or a lone irrigated farm within a predominantly arid mesoscale landscape. Fiebrich and Crawford (2001) documented frequent cool biases of up to $4^{\circ} \mathrm{C}$ downwind of irrigated cropland in Oklahoma. Likewise, within a flat to gently rolling mesoscale landscape, a station should not be sited near an extreme topographic or elevation change.

Another consideration for station siting is that optimal siting for one type of meteorological measurement may not be optimal for another. For instance, the World Meteorological Organization (WMO) recommends that a station should be no closer than 10 times the height of the nearest, large object, such as a stand of trees (World Meteorological Organization 2014a). While siting a station in this fashion affords ideal wind measurement conditions, it creates additional challenges for measuring snow (Ryan, et al. 2008; Fischer 2011). Figure 1 shows coincident snow-depth and wind gust measurements for two stations in Delaware during the same snow event on 7 January 2017. Note how the station in Fig. $1 \mathrm{~b}$ exhibits large swings in snow depth during gusty wind conditions while the station in Fig. 1a exhibits little or no variability under less gusty wind conditions. These large swings in snow depth are indicative of drift and scour effects from wind on the snowpack. Thus, while a station may be ideally sited for wind measurements, it may not be well sited for automated snow-depth measurements. The addition of an Alter screen (Alter 1937) around precipitation sensors is often the best solution in these circumstances. While each siting decision is commonly made on a case-by-case basis, a good rule of thumb is to give highest priority to the siting of the key climatic variables of temperature and precipitation when weighing conflicting siting criteria. 

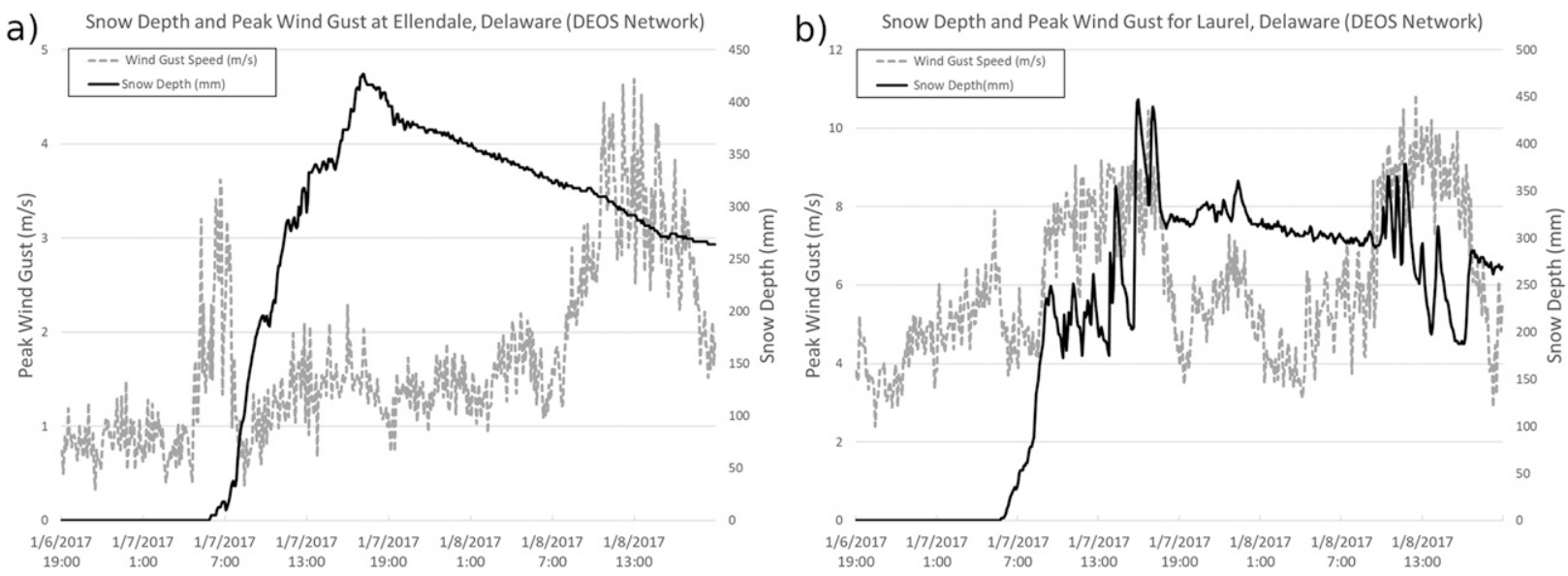

FIG. 1. Time series plots of 5-min wind gust (dashed line; $\mathrm{m} \mathrm{s}^{-1}$ ) and snow-depth (solid line; $\mathrm{mm}$ ) observations from the Delaware Environmental Observing System sites at (a) Laurel and (b) Ellendale on 6-8 Jan 2017.

In summary, mesonets, by their nature, sample weather at a spatial density and over a spatial extent that requires stations to be sited with a diversity of exposures. Mesonets should be designed to provide representative observations of complex environments and can only do so by incorporating stations with exposures that reflect that diversity, while retaining the ability to represent the mesoscale.

\section{b. Sensor siting}

Sensor siting refers to the position of sensors on the station platform and the shielding of those sensors, where appropriate. The following recommendations are provided for the siting of sensors deployed to measure variables commonly monitored by mesonets.

\section{1) AIR TEMPERATURE AND RELATIVE HUMIDITY}

Both air temperature and relative humidity should be placed at $1.5-2.0 \mathrm{~m}$ above ground in a ventilated, louvered shield to minimize radiational heating and cooling biases (Tanner 1990; World Meteorological Organization 2014b). As shown in Fig. 2, temperatures vary significantly in the lowest few meters of the atmosphere. The 1.5-2.0-m height is typically an area near the surface where gradients are minimal.

Fan-aspirated shields can be used to further reduce biases in air temperature measurements (Thomas and Smoot 2013). Because of the enclosed design of most fan-aspirated shields, network operators must be aware that a malfunctioning fan can lead to significant temperature errors. It is recommended that a fan be used that can report tachometer output (e.g., fan revolutions per minute) so that malfunctioning fans can be promptly replaced and affected temperature data can be flagged as erroneous. Over the 2010-19 period, the Oklahoma Mesonet noted a fan failure rate of $5.6 \%$ (i.e., 6.8 fan failures per year on average across 120 stations). Of these fan failures investigated, approximately one-third were associated with lightning damage.

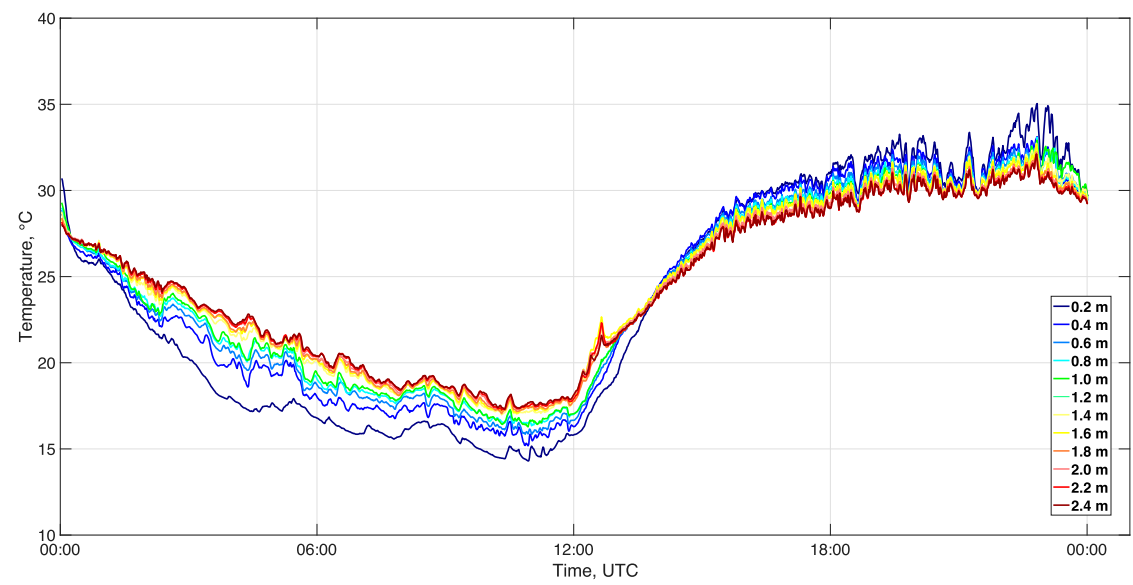

FIG. 2. Time series plot of 1-min air temperature data $\left({ }^{\circ} \mathrm{C}\right)$ collected by the Oklahoma Mesonet station at Norman on 30 Jun 2008 at the heights of $0.2,0.4,0.6,0.8,1.0,1.2,1.4,1.6$, $1.8,2.0,2.2$, and $2.4 \mathrm{~m}$ above the ground surface. The largest variability is observed in the lowest $1.2 \mathrm{~m}$, and the gradients tend to minimize between 1.5 and $2.0 \mathrm{~m}$. 


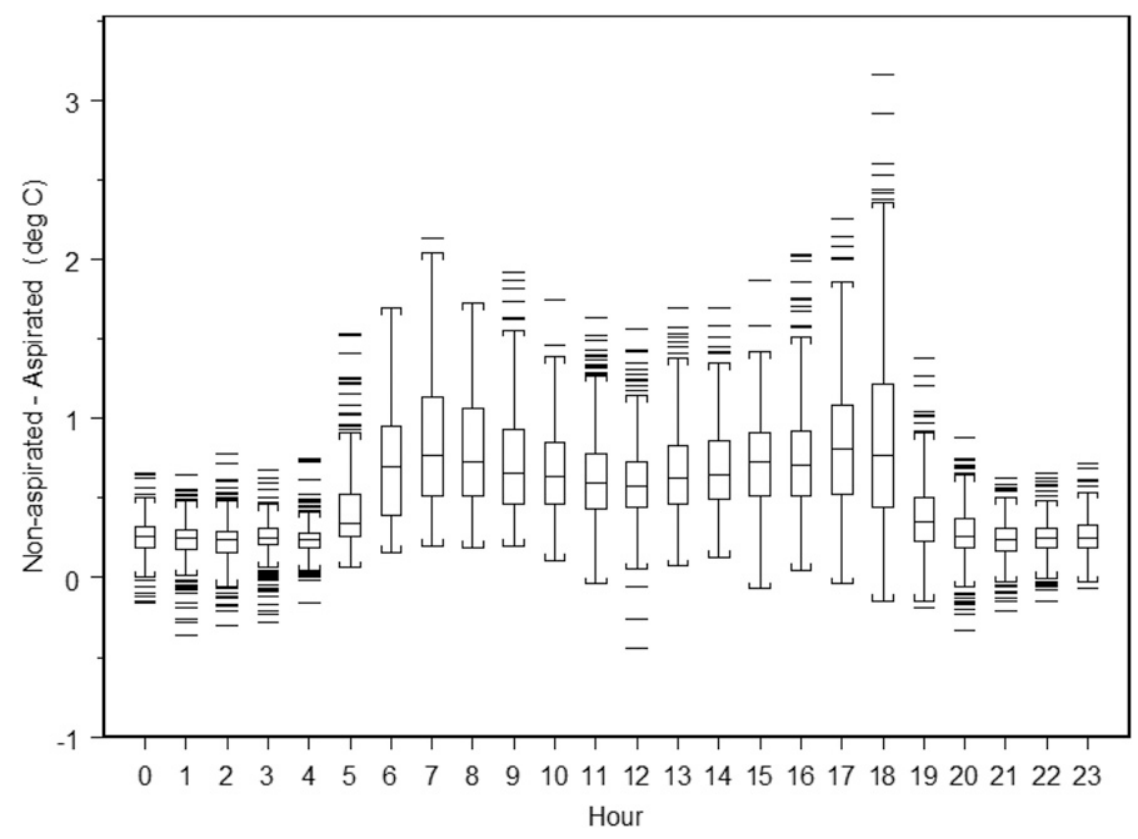

FIG. 3. Boxplots of the difference between natural-aspirated and fan-aspirated temperature observations from the Kentucky Mesonet station at Leitchfield during July 2019. Five-minute observations were binned by hour of the day (LT). Whereas median differences during overnight hours are approximately $0.5^{\circ} \mathrm{C}$, differences often exceed $1^{\circ} \mathrm{C}$ shortly after sunrise and shortly before sunset.

As can be seen in Fig. 3, radiational heating and cooling can cause errors in naturally aspirated shelters that frequently exceed $1^{\circ} \mathrm{C}$ in 5 -min mesonet data, with the greatest errors occurring within a few hours after sunrise and prior to sunset. Those times of day are most problematic because 1) sun angles are low and thus, solar radiation is more likely to enter the louvered sides of a radiation shield and 2) ambient winds are somewhat lower as compared to times of peak heating and mixing (Richardson et al. 1999). Proximate buildings, asphalt, concrete, shade, localized water bodies, and low-lying areas can result in microscale bias in temperature observations and should be avoided wherever possible.

Leeper et al. (2019) found that small-scale urban encroachment within close proximity of a station can have significant impacts on daily temperature observations. Therefore, stations should generally be sited at least $30 \mathrm{~m}$ from these and other sources of temperature bias when possible (National Oceanic and Atmospheric Administration 2018). For the purposes of measuring vertical temperature differences, it is recommended that identical air temperature sensors (Environmental Protection Agency 2000) be placed at $1.5-2.0$ and $9.0-10.0 \mathrm{~m}$ and/or at 1.0 and $3.0 \mathrm{~m}$. Care must be taken where wind speed and air temperature are observed at the same height to minimize the interference on wind measurements from the air temperature sensor's shielding.

\section{2) Precipitation}

The most common errors in precipitation measurements in mesonets include wetting/evaporative loss, wind effects
(World Meteorological Organization 2014b; Duchon and Essenberg 2001), and time-of-tip errors (Duchon et al. 2014). A substantially large precipitation gauge catch orifice (at least $15.4 \mathrm{~cm}$ in diameter) can help to minimize wetting and evaporative losses. To minimize wind effects, the gauge should be located at or below $2.0 \mathrm{~m}$ above the ground, except where necessary to avoid being buried by snow. Wind shielding should be installed to further reduce wind-induced undercatch of precipitation (Alter 1937). The gauge should be no closer than 2 times the height of any obstructions (buildings, trees, shrubs, etc.) (National Oceanic and Atmospheric Administration 2018).

\section{3) WIND SPEED AND DIRECTION}

Representative wind measurements require that a station be sited in an open area, since obstructions near wind instruments can dramatically reduce fetch and bias the observations (Haugland 2004). Figure 4 shows that wind speeds can be reduced by as much as $50 \%$ by clusters of trees as far as $200 \mathrm{~m}$ away from a mesonet station. General guidance is that obstructions should be no closer than 10 times the obstruction height relative to the station (World Meteorological Organization 2014a). At times, it is necessary to site mesonet stations closer to trees than defined by the WMO guideline in order for the location to be representative of the mesoscale. In these instances, siting metadata including panoramic and/or aerial photographs are important to document the site-specific wind anomalies. Significant obstructions to the wind are typically defined as objects with at least a $10^{\circ}$ horizontal aspect. 


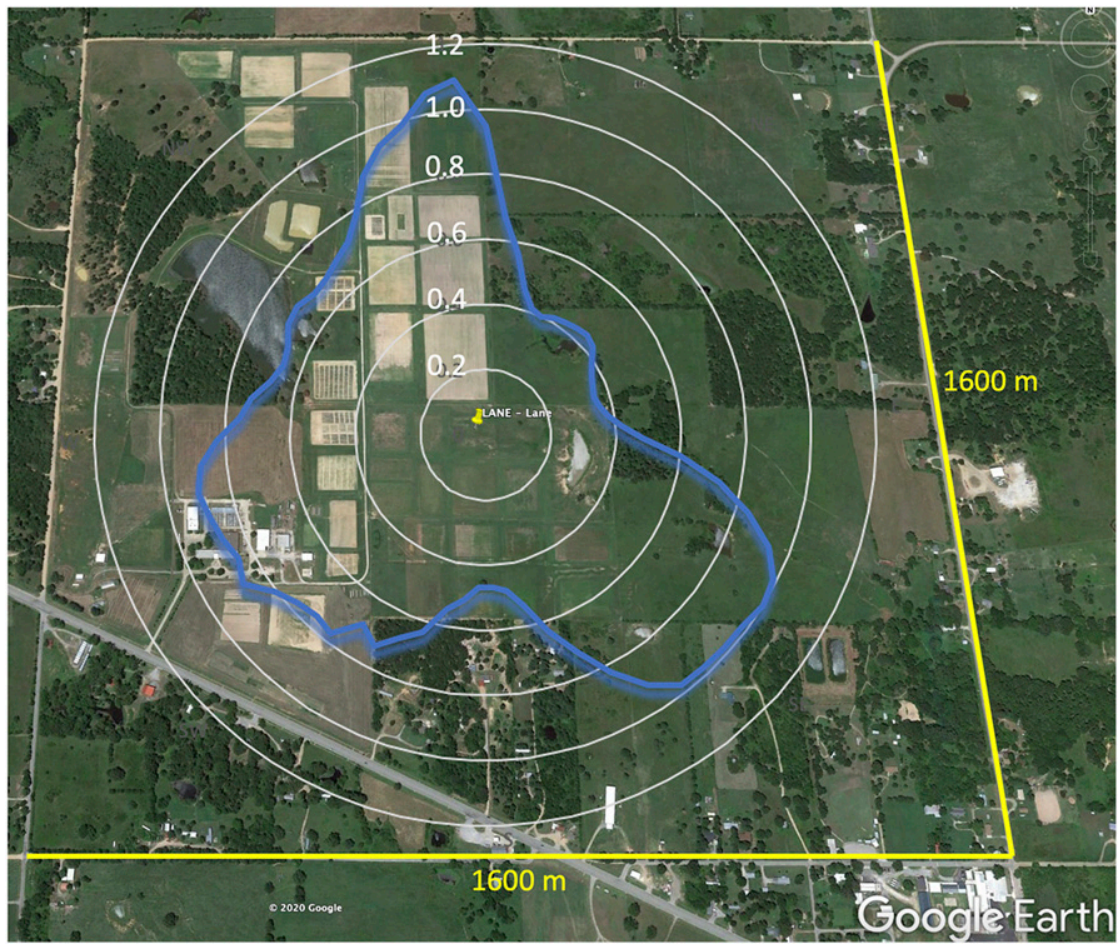

FIG. 4. Average wind speed at the Oklahoma Mesonet station in Lane normalized by the statewide average wind speed as a function of wind direction. Wind speeds from the south have magnitudes that are approximately $45 \%$ of the statewide average wind speed, and wind speeds from the southeast are approximately equal to (or $100 \%$ of) the statewide average wind speed Areas of trees 200-500 m away are present in any direction where wind speeds are diminished.

Knowledge of local climatological wind direction should be considered during site selection to accurately capture the most representative wind observations.

Given the boundary condition that wind speeds must decrease to zero at the ground surface, the magnitude of wind speed as a function of height generally follows the power law
(Brook and Spillane 1970; Justus and Mikhail 1976). Wind measurements should be taken at $10 \mathrm{~m}$ above ground (World Meteorological Organization 1993) as that is the height public forecasts are valid (National Weather Service 2019) and official wind speed, gust, and direction measurements are archived. As can be seen in Fig. 5, winds at $10 \mathrm{~m}$ are typically $30 \%$ greater

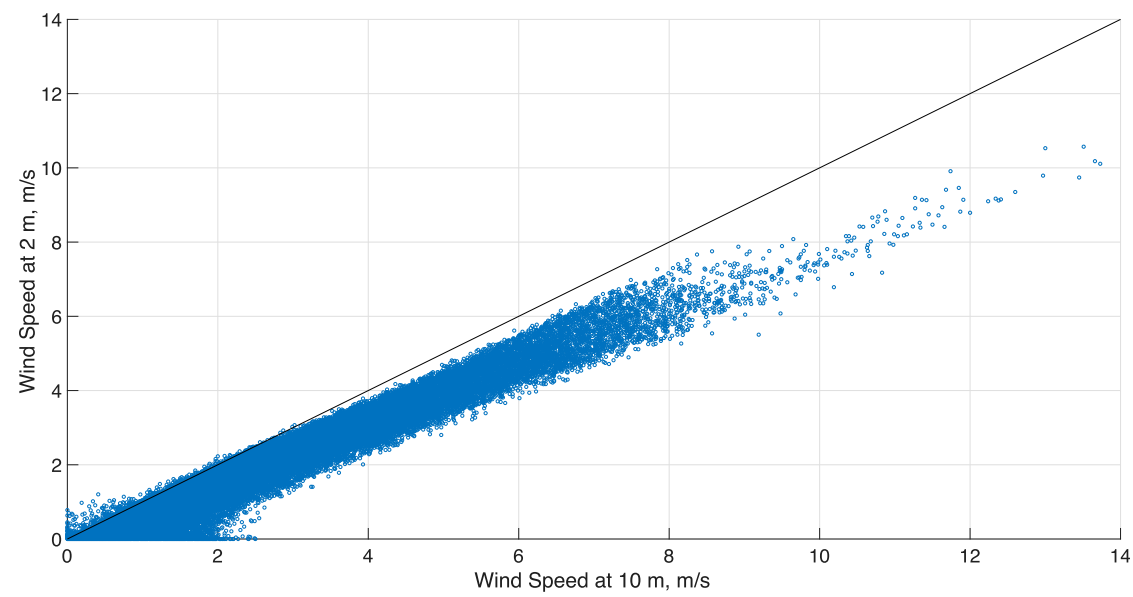

FIG. 5. Scatterplot of wind speed observations $\left(\mathrm{m} \mathrm{s}^{-1}\right)$ at 2 and $10 \mathrm{~m}$ between 1 Apr and 31 Oct 2019 at the Kentucky Mesonet station in Hickman. Wind speeds at $10 \mathrm{~m}$ are typically $30 \%$ greater than those observed at $2 \mathrm{~m}$. 
than winds at $2 \mathrm{~m}$. It is recognized that certain applications (e.g., reference evapotranspiration calculations) may necessitate wind measurements at additional heights, with $2-3 \mathrm{~m}$ being an additional useful measurement height.

\section{4) SOLAR RADIATION}

Solar radiation sensors should be positioned to avoid shade from sunlight during all times of year (i.e., placed on the south side of the tower for stations in the Northern Hemisphere). This includes selecting sites, where possible, to minimize the influence of large local obstructions on the horizon that would limit exposure to direct sunlight at sunrise or sunset. Exposure to nearby reflective objects should be avoided where possible, as this may also cause erroneous measurements. Solar radiation sensors should be placed on the instrumentation platform such as to minimize any obstruction by the instrumentation platform on incident solar radiation measurements. Guy wires used to anchor a station can sometimes produce momentary shading during the diurnal progression of the sun.

\section{5) AtMOSPHERIC PRESSURE}

Pressure measurements are recorded at many mesonet stations. These sensors are typically placed within the station's datalogger enclosure vented to the ambient atmosphere. Since most applications require reduction of station pressure measurements to sea level pressure, sensor height is not typically prescribed so long as the accurate elevation of the sensor is included for use in the pressure reduction equations.

\section{6) SOIL MOISTURE AND TEMPERATURE}

Soil moisture and temperature are operationally monitored at a variety of depths. Based on a survey conducted by the AASC (https://stateclimate.org/best-practices/) and the current depths measured by the U.S. Climate Reference Network, the Soil Climate Analysis Network, and the National Weather Service (NWS) Cooperative Observer Program (COOP) network (Bell et al. 2013), the most common depth is $10 \mathrm{~cm}$. Thus, where sampled at only one depth, soil temperature sensors should be installed at a depth of $10 \mathrm{~cm}$. Additional recommended depths are 5, 20, 50, and $100 \mathrm{~cm}$ (Schaefer et al. 2007). Soil moisture measurements should be taken under natural cover, but soil temperature measurements may be taken under either natural cover or bare soil. If possible, the physical properties of sampled soils should be representative of the most common soils of the area. When installing sensors, care should be taken to make sure soil sensors have good contact with the soil and that the soil profile is minimally disturbed during sensor installation.

\section{c. Metadata for station and sensor siting}

While following reliable guidance when siting stations is important, so too is collecting and maintaining detailed station metadata. The information available from metadata is key to determining the appropriateness of mesonet station data for use in certain applications, including the comparability of station data both within and between mesonets.

Suggested metadata elements related to a station's siting include station name, state and county Federal Information
Processing Standard (FIPS) code, NWS Weather Forecast Office (WFO) county warning area, internal station identifier, NWS location identifier, station latitude and longitude, method for acquiring horizontal datum, station elevation, method for acquiring elevation datum, parameters measured, site host information, vegetation type, land use/land cover, description of station surroundings (and/or panoramic photographs in eight cardinal directions), roughness classification, individual sensor measurement heights, types of structures sensors on which are installed, nonambient signal sources (e.g., nearby buildings, roads, or irrigation that could influence temperature or relative humidity observations), soil texture characteristics, and underground infrastructure (e.g., gas, water, or electricity lines that could influence soil sensor observations). While many of these elements are static, others are subject to change over time. Of particular note, changes in vegetation and in land use/land cover often become evident over a period of years. A detailed description of station surroundings should be updated as needed, and it is further recommended that site photographs be taken and archived on an annual or more frequent basis. Site metadata elements are typically updated following maintenance visits, as described below in section 4 .

\section{Sensor performance, sampling rate, and reporting rate}

The process of selecting sensors for deployment in a mesonet is inherently driven by considerations of performance and cost. Performance encompasses the operational range and accuracy, as well as reliability when the sensor is exposed to the various attributes of the operational environment for extended periods. Cost includes both the initial acquisition expense and the expected maintenance expenses prorated over the expected lifetime of the sensors.

The guidance presented herein regarding the selection of sensors is based primarily on operational range and accuracy, recognizing the role of cost considerations is unique to individual mesonets. Recommendations reflect an effort to synthesize the perspectives of the WMO (World Meteorological Organization 2014b), the mission of state mesonets as longterm environmental monitoring networks (Brock et al. 1995), and the current state of sensor technologies commonly used by mesonets throughout the United States. Besides sensor performance, this section also provides advice on sensor sampling and reporting rates. Finally, recommendations are included for documentation of sensor metadata.

\section{a. Sensors}

In the following sections, recommendations for sensors are provided for meteorological variables that are commonly measured by mesonets. Where appropriate, additional context is provided that might help to inform decision-making when selecting sensors.

\section{1) AIR TEMPERATURE}

Because of its stability, response rate, and precision, the platinum resistance thermometer (PRT) is the most commonly used instrument for primary temperature measurement in mesonets. As stable, accurate thermistors become available, 
their popularity is also increasing. Current air temperature sensing technology typically provides $\pm 1.0^{\circ} \mathrm{C}$ accuracy across the range from $-50^{\circ}$ to $-30^{\circ} \mathrm{C}, \pm 0.5^{\circ} \mathrm{C}$ across the range from $-30^{\circ}$ to $50^{\circ} \mathrm{C}$, and $\pm 1.0^{\circ} \mathrm{C}$ across the range $50^{\circ}-60^{\circ} \mathrm{C}$. Where air temperature measurements are necessary at two heights for purposes of inversion monitoring, the relative accuracy of the temperature sensors, not just absolute accuracy, is also a specification of importance. Thus, the temperature sensors in this scenario should be identical in make and model, be installed in the same type of shielding, and have matched calibration performance between the sensors of $\pm 0.1^{\circ} \mathrm{C}$.

\section{2) RelAtive HUMIDITY}

Capacitive hygrometers are the predominant sensors used for automated measurement of relative humidity $(\mathrm{RH})$ and are the preferred choice for mesoscale monitoring due to their ease of maintenance and calibration (World Meteorological Organization 2014a). It is often accepted that accuracy of relative humidity sensors should be $\pm 3 \% \mathrm{RH}$ across the operating range of $10 \%-90 \%$ and $\pm 5 \% \mathrm{RH}$ outside this range. Note that relative humidity sensors drift outside of tolerance in a shorter time span that most sensor types deployed in mesonets.

\section{3) WIND SPEED}

The most common types of wind sensors used at mesonet stations include cup anemometer and vane sets, combined anemometer and vane (i.e., propeller-based wind sensors), and ultrasonic wind sensors. Each of these types are acceptable. Wind speed accuracy of the anemometer should be $\pm 0.5 \mathrm{~m} \mathrm{~s}^{-1}$ below $5 \mathrm{~m} \mathrm{~s}^{-1}$ and better than $10 \%$ above $5 \mathrm{~m} \mathrm{~s}^{-1}$ (World Meteorological Organization 2014a), with a measurement range of $0-50 \mathrm{~m} \mathrm{~s}^{-1}$ and a measurement threshold of $1.0 \mathrm{~m} \mathrm{~s}^{-1}$. For wind direction, accuracy should be $\pm 5^{\circ}$ (World Meteorological Organization $2014 \mathrm{a})$, with a range of $0^{\circ}-360^{\circ}\left(5^{\circ}\right.$ potentiometer deadband maximum), and a measurement threshold of $1.0 \mathrm{~m} \mathrm{~s}^{-1}$.

\section{4) PRecipitation}

Tipping-bucket rain gauges or weighing rain gauges are both suitable sensors for measuring precipitation in mesonets. An unheated tipping-bucket rain gauge has been the mainstay of mesonets for decades. However, weighing rain gauges, using load cells or a vibrating wire's frequency, are commonly used in high-quality networks (e.g., U.S. Climate Reference Network; Gallo 2005). The orifice diameter of the gauge should be at least $15.4 \mathrm{~cm}$. Accuracy of any rain gauge should be at least $\pm 5 \%$ at rainfall rates up to $50 \mathrm{~mm} \mathrm{~h}^{-1}$.

Many mesonets operate in environments in which frozen precipitation is common. Weighing rain gauges are winterized using antifreeze to allow for precipitation measurements of frozen precipitation. Tipping-bucket gauges are typically unheated, as heating the gauge can lead to evaporative loss of melting snow, thus introducing bias in precipitation measurements (World Meteorological Organization 2014a). While weighing rain gauges are generally preferred to unheated tipping-bucket rain gauges in regions with frequent frozen precipitation, it is recognized that weighing gauges are significantly more expensive. Thus, many networks have employed unheated tipping-bucket rain gauges in areas frequently affected by frozen precipitation because of cost considerations. Care must then be taken when interpreting data from unheated rain gauges during winter precipitation. For instance, consideration should be given to reporting affected accumulations as "rain plus snowmelt" to avoid misinterpretation of the data.

Two of the most important factors associated with a rain gauge's accuracy are ambient wind speed effects and precipitation intensity. Wind speed effects on rain gauge measurements can be improved by decreasing the height of the rain gauge and/or by installing alter screens (Alter 1937) around the rain gauge. High precipitation rate events are often underreported by a tipping-bucket gauge. Because it takes up to $0.5 \mathrm{~s}$ for the bucket to rotate about its pivot point, undercatch can exceed $5 \%$ when rain rates exceed $100 \mathrm{~mm} \mathrm{~h}^{-1}$ (Duchon et al. 2014).

\section{5) BAROMETRIC PRESSURE}

Silicon capacitive barometers are the typical sensor for measuring barometric pressure in mesoscale networks. These sensors have the advantage of being low power and relatively stable over time. Accuracy of these sensors is $\pm 2 \mathrm{hPa}$, where air temperature is between $-40^{\circ}$ and $60^{\circ} \mathrm{C}$. The range of a barometer should be $700-1100 \mathrm{hPa}$ but could also require a lower minimum range if a station is located at high altitude. Outside of barometer accuracy, two factors can cause additional errors in pressure data: 1) some barometers exhibit a nonlinear temperature dependency that must be carefully corrected with calibration (Fiebrich et al. 2010) and 2) errors in site elevation metadata typically cause inaccuracy of approximately $0.1 \mathrm{hPa} \mathrm{m}^{-1}$ once the data are reduced to sea level pressure.

\section{6) SOLAR RADIATION}

Both thermopile-based and silicon photovoltaic sensors are used by mesonets to measure solar radiation. The most reliable and accurate options are thermopile-based pyranometers because of their spectrum performance and stability, particularly under cloudy conditions. Despite this, silicon photovoltaic sensors for solar radiation have widely been used in mesonets due to their small size, relatively low cost, and ease of maintenance. Heated pyranometers reduce error during frozen precipitation and condensation events. Absolute accuracy of solar radiation sensors should be $\pm 5 \%$ for daily totals with a range of $0-1500 \mathrm{~W} \mathrm{~m}^{-2}$ (American Society of Agricultural and Biological Engineers 2015).

\section{7) SOIL TEMPERATURE}

Soil temperature is typically measured using a thermistor designed for direct burial, often designed in combination with a soil moisture sensor. Accuracy of the sensor should be $\pm 0.5^{\circ} \mathrm{C}$ with a range from $-10^{\circ}$ to $60^{\circ} \mathrm{C}$ (note: mesonets located in cold climates may require a range from $-40^{\circ}$ to $60^{\circ} \mathrm{C}$ ). These specifications are important, but note that proper installation and maintenance of sensors are of particular importance, as soil erosion (Illston and Fiebrich 2017), soil cracking, and improper installation often lead to errors far greater than sensor accuracy. 

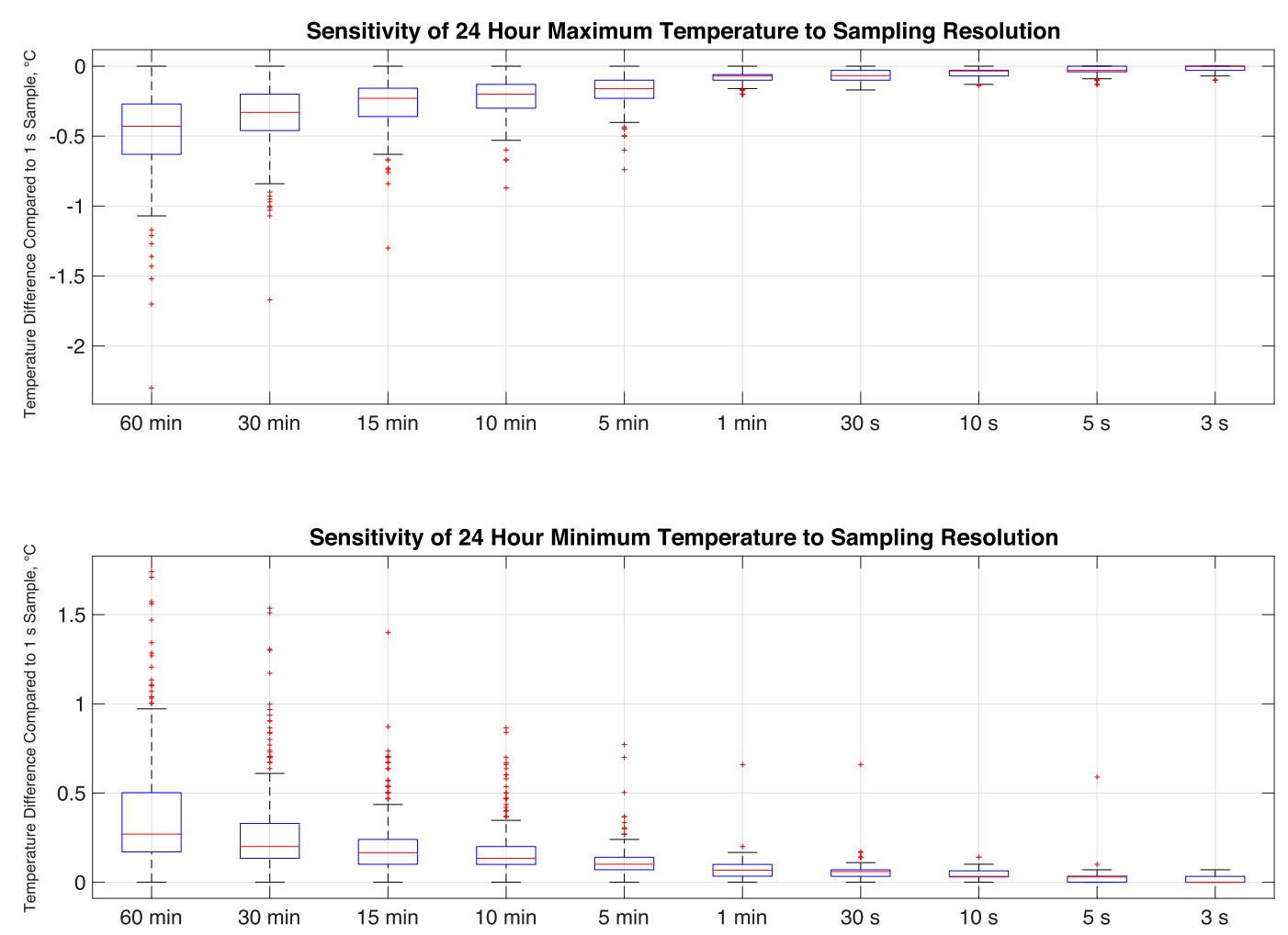

FIG. 6. Boxplot of the sensitivity of 24-h (top) maximum and (bottom) minimum temperature $\left({ }^{\circ} \mathrm{C}\right.$ ) as a function of sampling interval, based on data from the Oklahoma Mesonet station in Norman between 1 Nov 2004 and 30 Aug 2005. Hourly samples resulted in maximum and minimum temperatures that were as much as $1.0^{\circ} \mathrm{C}$ different than those calculated from 1-s samples (i.e., the range of the whiskers of the boxplots).

\section{8) SoIL MOISTURe}

The two most common soil moisture parameters observed by mesonets are volumetric water and matric potential. While volumetric water relates to the absolute fraction of water in the soil, matric potential refers to the force plants require to extract water from the soil (Dingman 1994; Illston et al. 2008). Volumetric water content (VWC) can be measured using various methods [e.g., coaxial impedance dielectric reflectometry (CIDR), time-domain reflectometry (TDR), and frequency domain reflectometry (FDR)]. Accuracy of a VWC sensor should be $\pm 0.03 \mathrm{~m}^{3} \mathrm{~m}^{-3}$, and it should be capable of capturing the full range of soil water content values for a location's representative soils and a sensing volume diameter less than $5 \mathrm{~cm}$.

As is the case with soil temperature measurements, proper installation of soil moisture sensors is important (Basara and Crawford 2000). Challenges with soil erosion, soil cracking, vegetation impacts, and improper installation often lead to errors far larger than sensor inaccuracy. When measuring volumetric water content, soil properties are key metadata in assessing drought and plant available water. For instance, a volumetric water content of $0.2 \mathrm{~m}^{3} \mathrm{~m}^{-3}$ indicates wet conditions in sandy soils while indicating dry conditions for clay soils. Additionally, some sensors have uniquely different calibration equations dependent on soil type.

\section{9) SNOW DEPTH}

Snow depth can be measured by laser, sonic, or photographic sensors. Each of these is acceptable. For laser distance sensors, the typical accuracy is $\pm 1 \mathrm{~mm}$, while sonic depth sensors are $\pm 1 \mathrm{~cm}$. Photographic sensing, which uses cameras to take images of snow relative to markers of known height and distance from the camera device, are typically less accurate $( \pm 2.54-5.08 \mathrm{~cm})$. Because of uneven accumulation associated with drifting, it is difficult to obtain automated measurements that are both accurate and representative. Recognizing this, a sensor with accuracy within $\pm 2.54 \mathrm{~cm}$ is recommended.

\section{b. Sampling and reporting rates}

The observations recorded by a mesonet station's datalogger are based upon sampled values. In general, a 3-s sampling rate for sensor measurements and 5-min reporting rate for processed observations are recommended. The 3 -s sampling rate is particularly important for the measurement of air temperature and wind gusts. Figures 6 and 7 display the impact of varying sampling rates for temperature and wind speed. For slowly changing variables, such as barometric pressure and soil moisture, or for sensors with high power demands, less frequent sampling and reporting are adequate.

Table 1 summarizes much of the performance information for each sensor detailed in this section. The table includes operating ranges, accuracy, reported resolution, sampling rate, 
Effect of Sampling and Averaging Intervals on

Ratios of Maximum to Average Wind Speed

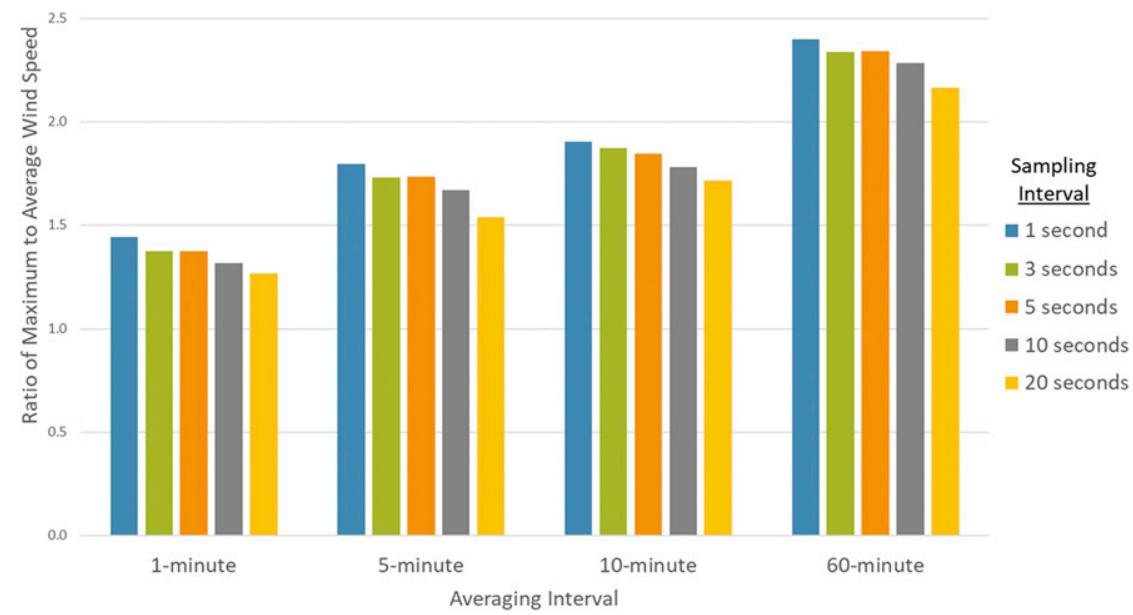

FIG. 7. Effect of sampling interval $(1,3,5,10$, and $20 \mathrm{~s})$ and averaging interval $(1,5,10$, and $60 \mathrm{~min}$ ) on the ratio of peak wind gust (maximum) to average wind speed for a Delaware Environmental Observing System station in Newark during the period 21 Oct 2013-25 Nov 2013. As the averaging interval increases, the ratio of peak gust to the average wind speed increases.

and reporting rate. Preferred sensor types for each variable are also included. The "accuracy" terminology used in this section is an expression of uncertainty, although it is a concept somewhat open to varying interpretations. The accuracies listed are expressed in terms of uncertainty by an error propagation analysis (Lin and Hubbard 2004; Taylor and Kuyatt 1994). Note that external factors can cause field accuracy to be worse than the sensor accuracy that is provided in a sensor manufacturer's specifications. Also, it is assumed that all sensors must operate in the following environmental conditions to reliably perform in a mesonet: air temperatures from $-40^{\circ}$ to $55^{\circ} \mathrm{C}$ (ideally from $-60^{\circ}$ to $55^{\circ} \mathrm{C}$ for cold climates), relative humidity between $1 \%$ and $100 \%$, pressure between 700 and $1100 \mathrm{hPa}$, and wind gusts up to $50 \mathrm{~m} \mathrm{~s}^{-1}$.

\section{c. Sensor metadata}

A number of metadata elements that describe the sensors used in a mesonet can be helpful when interpreting observational data. These metadata include sensor model, measurement units, sensor installation date, sensor shielding, and sensor data averaging/processing procedure. For stations with multiple sensors measuring the same parameter at different heights or depths, separate metadata entries are recommended for each sensor that is deployed.

\section{Maintenance}

The quality of data produced by a mesonet station is fundamentally linked to the network's commitment to maintenance activities. These activities include preventative maintenance of sensors, unscheduled maintenance as dictated by quality assurance and quality control triggers, and general site maintenance. It is recommended that mesonet operators document their station maintenance practices in a transparent way as an additional means to provide quality information to users. This section provides recommendations regarding the development, implementation, and documentation of maintenance activities.

\section{a. Preventative maintenance}

Regularly scheduled visits to mesonet sites to perform preventative maintenance can greatly improve station reliability and data quality (Fiebrich et al. 2006). The typical interval for preventative maintenance visits varies from monthly to seasonally to annually among different networks, generally based on the speed of vegetation growth, impact of harsh climate conditions, insect infestations, and resources available. Typical tasks conducted during preventative maintenance include management of vegetation, sensor rotations, sensor leveling and cleaning, servicing fluids in precipitation gauges, field functionality tests, in-field calibrations, documenting the station with digital photographs, and hardware inspections.

Most sensors have recommended rotation intervals provided by the sensor manufacturer. Figure 8 displays the drift detected in 162 relative humidity sensors calibrated in the Oklahoma Mesonet laboratory between June 2015 and December 2019. Such data can help a network pinpoint the best rotation interval for their particular region. Sensors due for calibration should be replaced if they cannot be calibrated in the field.

The preventative maintenance visit is also an efficient time to (i) perform in-field calibrations or checks and (ii) conduct metadata audits. Tolerances for each instrument's calibration performance should be defined to assess compliance. Note that 


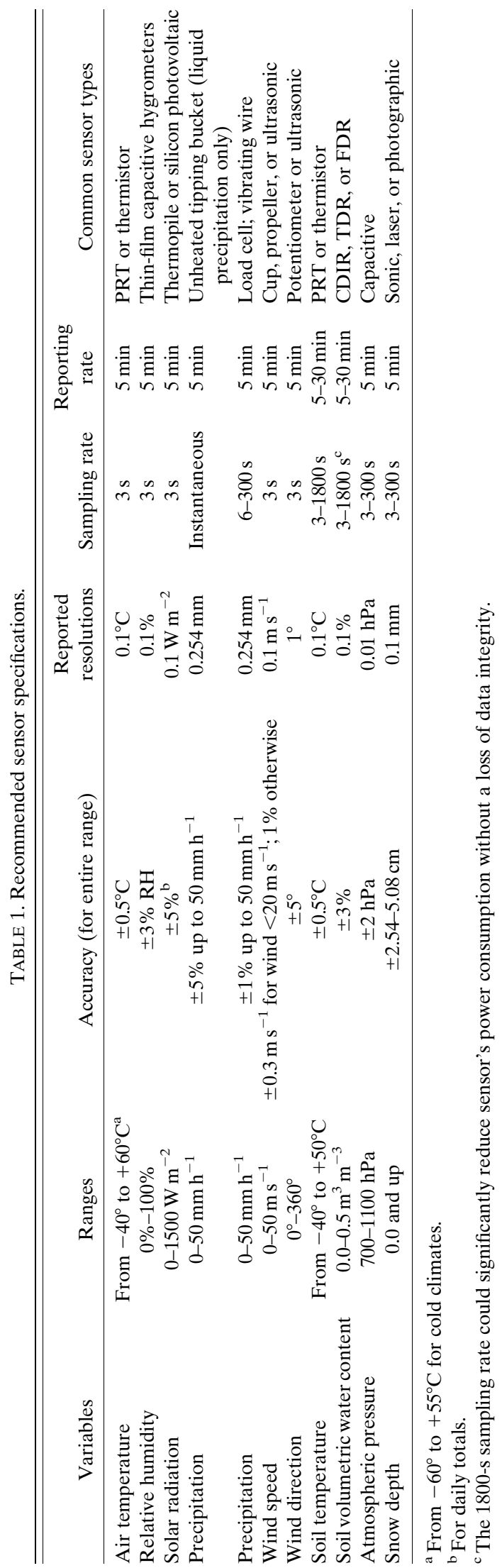

not all sensors (e.g., soil moisture and soil temperature sensors) can be audited or recalibrated because of undue disturbance caused by accessing the sensors.

\section{b. Unscheduled maintenance}

Unscheduled maintenance visits are required when data deterioration or loss is identified by quality assurance protocols. Given the demands and requirements for mission-critical applications, it is recommended that mesoscale networks establish priorities and associated deadlines for restoring sensors or stations to normal functional status. Table 2 details common maintenance problems associated with the standard sensors on a mesonet tower.

\section{c. General maintenance}

A number of general maintenance practices are recommended to ensure suitable station performance. Photographic documentation of "as found" and "as left" site conditions for each site visit are useful for recording the history of maintenance activities. In addition, careful notation of serial numbers and models of sensors installed and removed, as well as work performed at the site during the visit should be documented as critical metadata. Each station in a network should be visited at least once a year by a trained technician to ensure all aspects of the station are fully functional and that all annual metadata elements are inventoried properly. Vegetation and fauna maintenance (e.g., grass cutting, herbicide application for nonnative weeds) or specific sensor requirements may require more frequent visits throughout the year.

\section{d. Metadata for station maintenance}

When well documented, the metadata collected and archived that describe station maintenance enable a data user to reconstruct the circumstances and conditions that may affect the time series of meteorological observations collected at a given station. Recommended metadata elements include overall network information (e.g., description of general maintenance procedures performed and general maintenance frequency), as well as specific information for each site visit (e.g., date of maintenance, description of work performed, and staff member performing the maintenance).

\section{Quality assurance}

Quality assurance (QA) of mesonet data typically encompasses the broad efforts of a mesonet to ensure proper station siting, station maintenance, sensor calibrations, and automated and manual methods for evaluating the resultant observations. Many of those aspects have been covered in the preceding sections; thus, this section focuses on the automated and manual data evaluations. Generally, a mesonet's quality control (QC) system will consist of software algorithms that assess the accuracy and representativeness of sensor data through real-time and periodic tests in order to detect sensor problems or failures. Since not all data can be perfectly assessed using automated software algorithms, manual assessment through quality assurance procedures is also required and should be performed by trained professionals. 


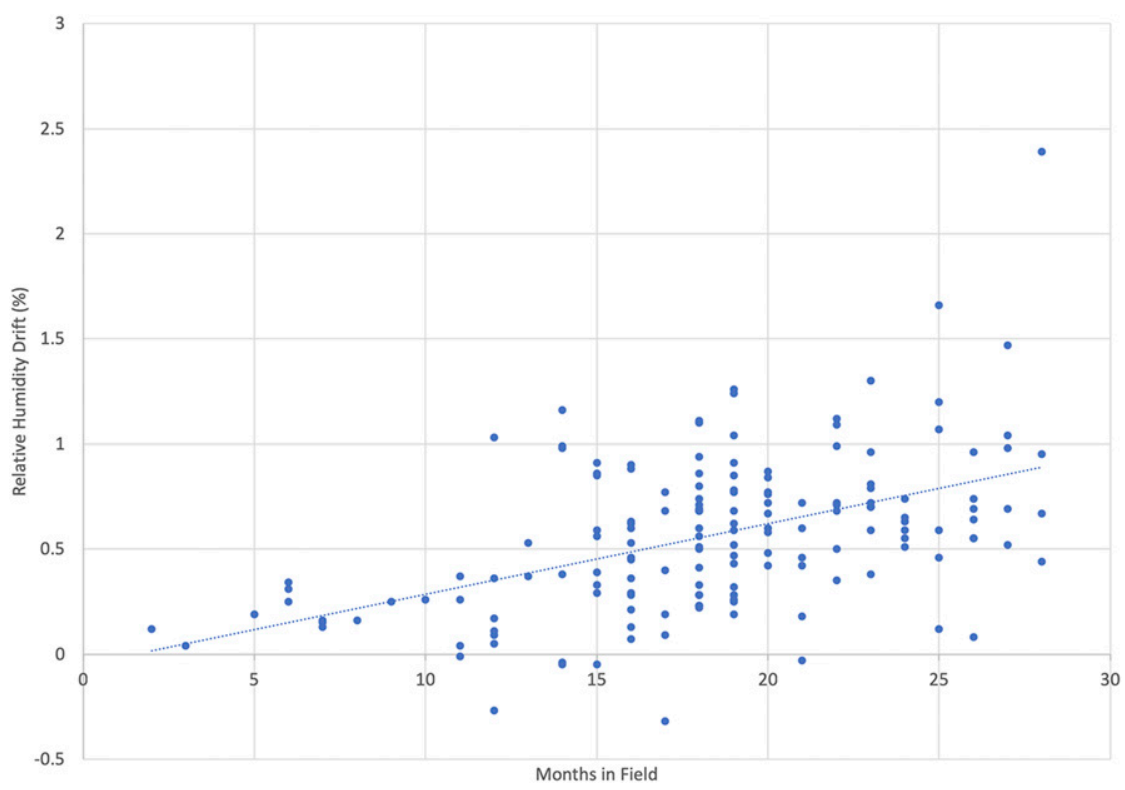

FIG. 8. Change in mean error in relative humidity ( $\%$ ) as a function of months in the field for relative humidity sensors calibrated at the Oklahoma Mesonet laboratory between June 2015 and December 2019. Dotted blue line indicates the linear-regression best-fit line.

The following recommendations aim to provide general guidance, recognizing that specific implementation of methods may vary based on the environmental nuances of individual mesonets, as well as budgetary and staffing constraints.

\section{a. Automated quality control}

Automated quality control is broadly composed of five categories: 1) physical limits range tests, 2) seasonal limits range tests, 3) sensor intercomparison tests, 4) temporal consistency tests, and 5) spatial coherency tests. A summary of quality assurance procedures used commonly across the United States for mesoscale meteorological data is detailed in Fiebrich et al. (2010).

Physical limits tests are typically based on the operating ranges of the specific sensors deployed within a mesonet but can also be based on a reasonable expectation of climate extremes in a mesonet's region. For instance, if a sensor cannot measure air temperatures above $50^{\circ} \mathrm{C}$, then screening data for values above this threshold would be necessary, as sensor values above this threshold would be unreliable.

Seasonal range tests are based on extremes in the climatological archive and are intended to reduce the likelihood that physically possible, but highly unusual sensor values are accepted without further review. It is common for some overlap to exist in the ranges and thresholds of physical limits tests and seasonal range tests. Some networks that do not have a 30-yr history adopt climatological data from a neighboring National Weather Service COOP station (National Weather Service 2003).

Sensor intercomparison tests compare data values between redundant sensors (e.g., two collocated rain gauges) or between sensors mounted at different heights (e.g., soil temperatures at 5 and $10 \mathrm{~cm}$ ). Figure 9 shows a comparison of dual rain gauge data recorded during a precipitation event on 11 January 2020 across Oklahoma. Gauges that reported rainfall that differed by more than $5 \%$ (e.g., TULN

TABLE 2. Common maintenance problems associated with standard sensors on a mesonet tower.

\begin{tabular}{|c|c|}
\hline Sensor & Common maintenance problems (excluding sensor drift) \\
\hline Air temperature & $\begin{array}{l}\text { Failed or blocked aspirator, degraded or cracked radiation shield, insect nest around sensor, or } \\
\text { moisture intrusion into sensor components }\end{array}$ \\
\hline Relative humidity & Degraded or dirty sensor filter or chip; moisture condensation onto sensor components \\
\hline Solar radiation & Sensor out of level; dust or debris on sensor \\
\hline Precipitation & $\begin{array}{l}\text { Gauge clogged with debris, failed tipping-bucket switches, insect web causing tipping buckets to be } \\
\text { immobile, gauge out of level, or weighing bucket misaligned }\end{array}$ \\
\hline Wind speed and direction & Degraded bearings; physical damage from hail or ice accumulation \\
\hline Soil temperature and moisture & Rodent or underground animal damage; soil erosion or deposition \\
\hline Pressure & Clogged inlet tube \\
\hline Snow depth & Sensor out of level; broken/missing snowboard \\
\hline
\end{tabular}




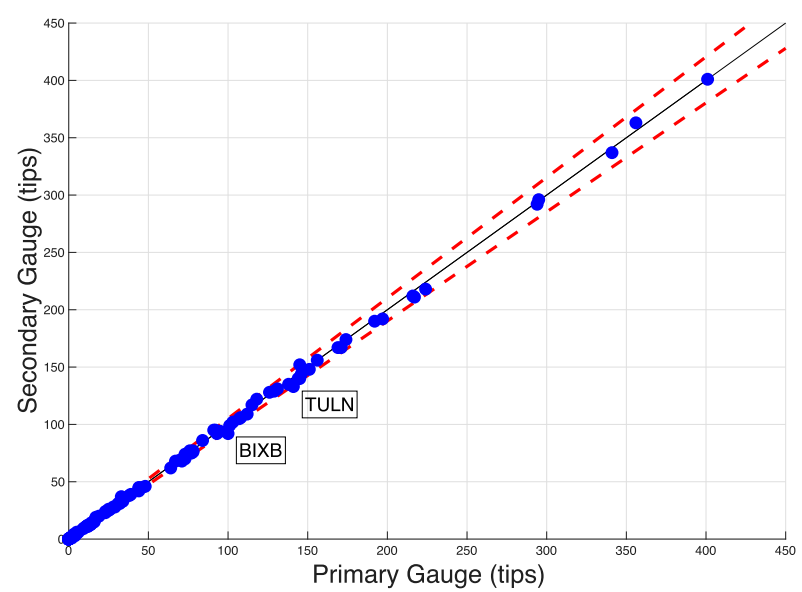

FIG. 9. Scatterplot of tipping-bucket rainfall data observed by dual gauges at each station in the Oklahoma Mesonet during a rain event on 11 Jan 2020. The stations Bixby (i.e., BIXB) and Tulsa North (TULN) were highlighted for further review because the gauges at those sites differed by more than $5 \%$ (dashed red lines).

and BIXB) are highlighted so that their data can be further reviewed. Sensor intercomparison tests can also be helpful in identifying sensors that respond inconsistently to certain environmental conditions (e.g., an observation of extremely low relative humidity values coincident with significant rainfall).

Temporal consistency tests assess how much a sensor's observations change over a set duration of time. These types of tests are sometimes referred to as "delta," "step," or "persistence" tests. Like most automated tests, these tests may be regionally specific, as the expected rates of change in some environmental parameters differ significantly depending on the general climate of an area. Large, dramatic changes in sensor data may indicate a problem, such as a sensor failure. Likewise, data that do not exhibit variability (e.g., wind observations that remain at $0 \mathrm{~m} \mathrm{~s}^{-1}$ for more than $24 \mathrm{~h}$ ) can be flagged for manual review by QA staff.

Spatial coherency tests (e.g., "buddy checks") assess the similarity of a station's sensor data to those recorded by neighboring stations. When properly implemented, spatial coherency tests are useful for identifying sensors that have drifted out of calibration or are experiencing an operational issue, such as a clogged rain gauge. However, it is critical to consider the degree of similarity in the mesoscale climate between proximate stations, as stations that differ in their mesoscale siting exposure can reflect distinctly different meteorological influences. In instances where proximate stations have significantly different meteorological influences, spatial coherency test thresholds may need to be adjusted. Hence, site metadata should be used when selecting stations for comparison so as to minimize the inadvertent flagging of data as suspect or erroneous when the values are valid.

The aforementioned general categories of automated QC address the vast majority of sensor data problems. However, as

\section{Solar Radiation at Brookings, South Dakota}

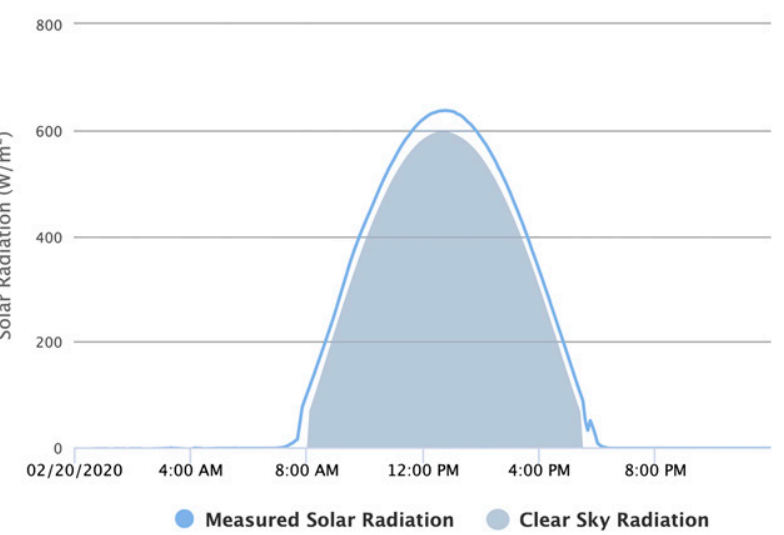

FIG. 10. Time series plot of solar radiation $\left(\mathrm{W} \mathrm{m}^{-2}\right)$ as reported by the South Dakota Mesonet station in Brookings plotted along with theoretical clear-sky radiation (filled area) calculated for the time, location, pressure, and vapor pressure according to FAO-56 (Allen et al. 1998). The sensor reported consistently elevated values (more than $5 \%$ ) when compared with the calculated clearsky radiation on confirmed clear-sky days, indicating that it was misaligned or in need of calibration.

noted above, location- and region-specific quality control tests can help to address influences of unique mesoscale features, such as terrain/elevation differences, proximity to water bodies, as well as urban areas and irrigated agriculture. Thus, automated QC procedures can be applied universally for all stations in a mesonet or they can exclude some stations because of unique or unusual mesoscale features. Ultimately, each mesonet's automated QC system will require regional-specific thresholds. However, as a best practice, mesonets should aim to develop and appropriately employ QC in each of the five previously mentioned categories.

\section{b. Manual quality control}

Manual QC can provide additional ways to detect sensor problems. Aggregating and plotting monthly statistics (e.g., maximums, minimums, accumulations) can sometimes reveal subtle biases that may go undetected in the real-time data stream. Additionally, analyzing plots of monthly averages at a well-mixed time of day (e.g., average monthly temperature of all stations in a region at noon) can allow for stringent manual assessment of the observations. Confidence in mesonet data quality can also be assessed by comparing the observations to data from external data sources. Some external sources include satellite data, radar [NEXRAD and Terminal Doppler Weather Radar (TDWR)], Real-Time Mesoscale Analysis (RTMA), and other observation networks such as the Community Collaborative Rain, Hail and Snow (CoCoRaHS; Reges et al. 2016), backyard weather stations, and Automated Surface Observing Systems (ASOS; National Oceanic and Atmospheric Administration 1998). Figure 10 illustrates a manual quality control technique used to detect erroneous data from a pyranometer through comparison with theoretical data. Table 3 provides additional examples of sensor-specific manual QC 
TABLE 3. Suggested manual quality control strategies for standard sensors on a mesonet tower.

\begin{tabular}{lc}
\hline \hline \multicolumn{1}{c}{ Sensor } & Suggested manual QC strategies \\
\hline Air temperature & Calculate potential temperature for spatial comparisons in areas of significant terrain; compare \\
observations with other networks and NOAA's RTMA product \\
Inspect monthly max relative humidity observations on nights when dew is known to have formed; \\
convert relative humidity to dewpoint for spatial comparisons \\
Compare with theoretical clear-sky solar radiation estimates; compare monthly maximum values \\
before and after rain events to reveal dirty sensors; assess magnitude of values with visible \\
satellite data \\
Ensure physical consistency with relative humidity and soil moisture observations; compare rainfall \\
totals with radar-estimated rainfall; compare rainfall start and end times with radar reflectivity; \\
conduct double mass analysis (Martinez et al. 2004) between neighboring stations over an annual \\
period; compare values with CoCoRaHS and other station networks \\
Assess percentage of data with calm winds; compare with air temperature and precipitation during \\
freezing precipitation; compare with known locations of fronts, boundaries, and convective \\
outflows \\
Inspect soil moisture observations during times when soils are frozen; overlay time series plots of \\
soil temperatures at varying depths to ensure expected diurnal soil heat flux \\
Corroborate large pressure increases or decreases with radar data to identify potential mesolows or \\
mesohighs associated with convective storms; compare trends with neighboring stations during \\
frontal passages \\
Ensure near-zero reports during periods without snow cover; inspect snow-depth changes as a \\
function of wind gusts; compare snow rates relative to radar reflectivity; compare with available \\
camera imagery as well as manual reports from CoCoRaHS or COOP observers
\end{tabular}

strategies that have been useful to identifying erroneous mesonet observations. Figure 11 shows a manual quality control method used to detect a malfunctioning precipitation gauge by comparing rainfall observations with soil moisture observations.

\section{c. Quality control flags}

In conjunction with a range of quality control tests, mesonets are strongly encouraged to adopt a flagging structure to indicate varying levels of confidence in the quality of each observation (e.g., good, good despite failing automated QC, suspicious, bad, and bad despite passing automated QC). Additional data flags that indicate when maintenance is performed at a station is also recommended. Such data flags generally provide the necessary information for the data user to describe the fitness of the data for use in their application and allows for a more universal understanding of data quality across all mesonets. While automated QC tests can generate varying levels of QA flags, it is recommended that the automated results be reviewed by trained QA staff, preferably with meteorological experience, within a reasonable time frame to ensure the timeliness and continuity of a mesonet's data quality. The flags "good despite failing automated QC" and "bad despite passing automated QC" provide a flag value that communicates to the data user that a suspect data value has been reviewed by a QA staff member. For each manually reviewed data value, comments explaining the reason for changing the flag value of the data should be recorded along with the flag value. This provides data users with additional, corroborating information to determine the fitness of the data for their needs. It should be noted that the majority of data users will simply want the network to provide them only good data while screening out (or indicating "unavailable") any observations that are deemed erroneous.

\section{d. Metadata for network quality assurance/quality control procedures}

The recommended metadata that should be documented include 1) a detailed description of the QA procedures and QC tests performed and 2) a list of the QC flags and descriptions. While very general, these items communicate how to interpret the quality of a network's data to its data users.

\section{e. Metadata for sensor calibration procedures}

Mesonet operators should strive to provide basic metadata about the calibration of the sensor deployed. The suggested metadata items include descriptions of the calibration procedures, as well as the sensor calibration frequencies. It is expected that calibration metadata will be needed for each type of sensor in a network, as different sensors may have different procedures and/or calibration frequencies. In addition, it is recommended that networks maintain internal metadata of the results of sensor calibrations, including infield calibration tests.

\section{Data processing}

Mesonets provide a wide variety of detailed environmental data and information for making informed weatherand climate-related decisions. To be effective in application, such information should be credible, available in a timely manner, reliable, useable, useful, expandable, sustainable, responsive/flexible, and authentic (World Meteorological Organization 2014c). Thus, it is important that networks follow consistent methods for data processing with regard to handling missing data, aggregating observations to create 
A. June 13-14, 2017 Lake City

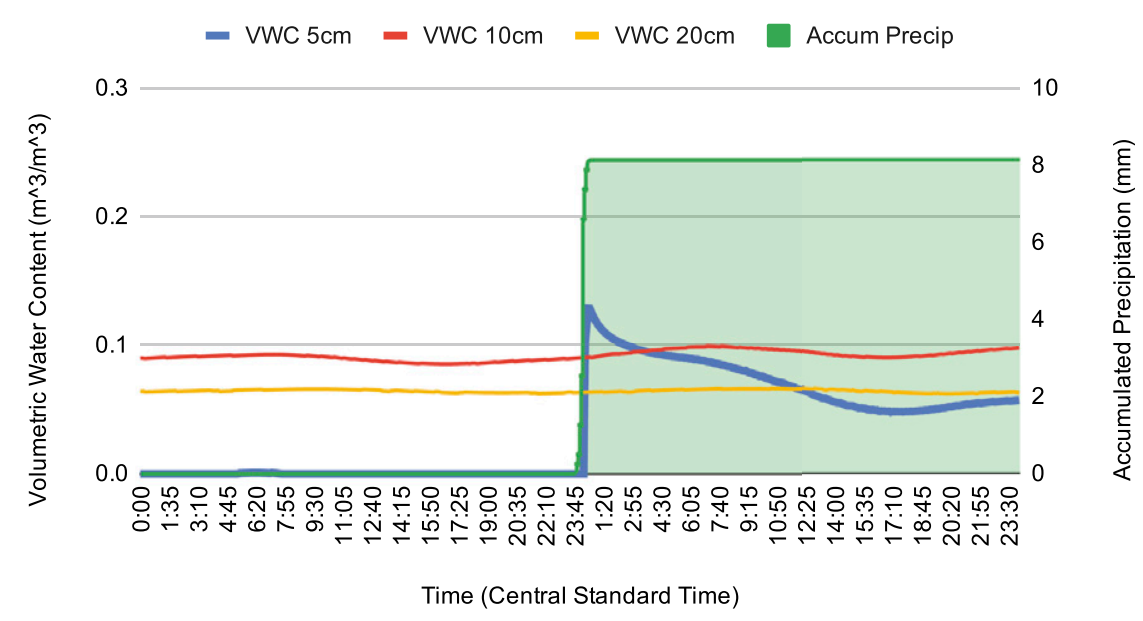

B. July 7-8, 2017 Lake City

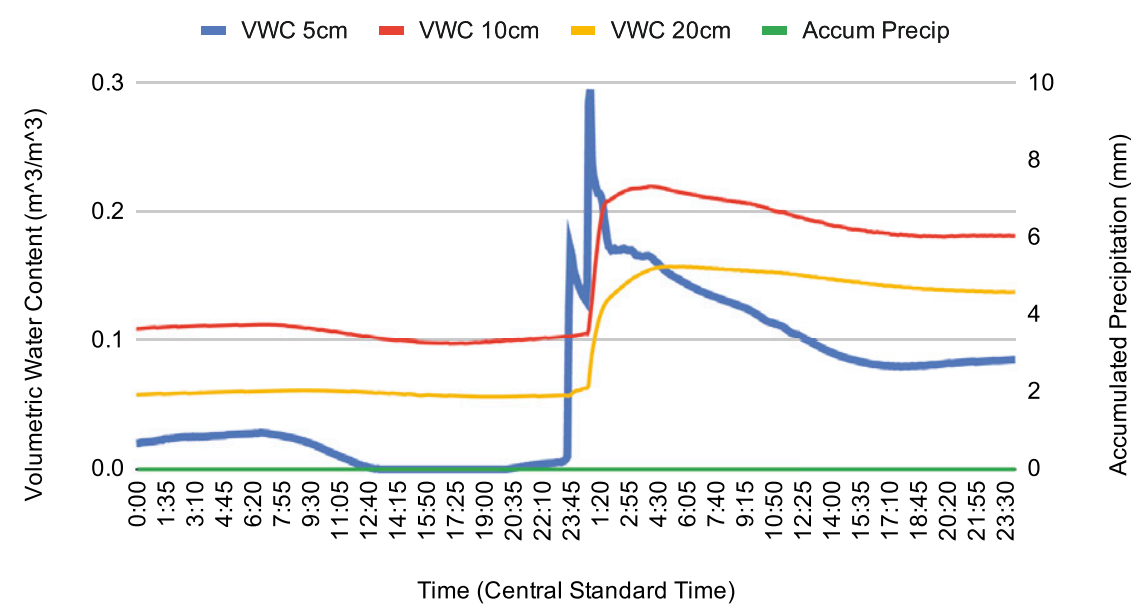

FIG. 11. Time series plots of volumetric water content $\left(\mathrm{m}^{3} \mathrm{~m}^{-3}\right)$ and accumulated precipitation ( $\mathrm{mm}$ ) as reported by the Kansas Mesonet station in Lake City for (a) 13-14 Jun and (b) 7-8 Jul 2017. In (a), the volumetric water content at $5 \mathrm{~cm}$ increased when the accumulated precipitation increased. In (b), the volumetric water content at 5,10 , and $25 \mathrm{~cm}$ increased without a coincident increase in accumulated precipitation. This alerted staff to a gauge problem during the 7-8 Jul 2017 event.

summary variables for hourly, daily, and longer timeframes, and ensuring that data are offered in a reliable fashion.

\section{a. Operational data reliability}

Usage of weather and climate information can be generally classified into two broad categories. The first is strategic, which includes products that aid in the general long-term planning and design of projects and policies. The second is tactical, which includes products and data that aid in solving short-term, specific, immediate problems (World Meteorological Organization 2018). As such, data reliability and completeness are key attributes for any mesonet. Data completeness also encompasses ensuring that the appropriate number of samples are available in computing the reported 5-min observations. Operators should be mindful to ensure that appropriate samples are available, and ideally, all samples should be available when calculating the official observations (particularly with respect to variables where dynamic or cumulative values are of concern).

One such application that requires the delivery of reliable, high-quality mesonet data is NOAA's National Mesonet Program (NMP; Callahan and Klopcic 2011; Marshall 2016; Woll 2018), which integrates nonfederal weather data with data from federal networks to create more comprehensive, improved operational weather and climate products. The NMP requires a monthly operational network data availability and completeness of $95 \%$ or greater. It is recommended that 
mesonets strive to meet or exceed an operational reliability threshold of $95 \%$ or greater data completeness for any $60-\mathrm{min}$ period, for all stations in the network in order to consistently meet data user and application needs.

\section{b. Aggregating mesonet data into hourly, daily, and longer-term statistics}

Consistency in computing hourly, daily, or longer-term statistics from core, 5-min mesonet observations is crucial to ensuring data remain useful for climate monitoring and other data applications where subtle differences in methods can result in significant differences in trends and results. Data aggregation method and data completeness thresholds are important in deriving consistent statistical data. Incomplete data (i.e., missing observations) can be introduced by a sensor, datalogger, telemetry, or other system malfunction. Subsequent problems associated with missing observations range from an incomplete data archive to erroneous application of the data. It is important to note that missing observations are more critical for some environmental variables than for others. This is especially true for extremes or precipitation totals.

The limits on the permissible number of missing observations in a given application vary greatly depending on the application and the amount of error a user is willing to accept (Anderson and Gough 2018). However, to remain consistent with the National Weather Service ASOS network, it is recommended that mesonets require $75 \%$ completeness for calculating data at the hourly or smaller time step for all noncumulative parameters (National Oceanic and Atmospheric Administration 1998). Alternatively, mesonets may provide the percentage of missing observations during the reported time period to its data users.

Calculation of hourly, daily, and monthly values should only be derived from a mesonet's core 5-min observations (or longer observation time in some cases, such as soil temperature and soil moisture measurements). It is recommended that mesonets follow the convention utilized by NOAA's National Centers for Environmental Information (NCEI) to derive monthly values. This convention states that a monthly mean value should not be calculated if there are more than five total days or more than three consecutive days of missing values. Adapting this method to a network's typical 5-min data, daily mean values should be derived only if no more than four hours of 5-min data are missing and no more than three consecutive hours of 5-min data are missing. In the case of elements for which the monthly value is a sum of daily values (e.g., precipitation), NCEI provides monthly totals along with the number of missing daily values, and notes if there are any multiday totals included in the monthly total (M. Menne 2018, personal communication). It is recommended that mesonets follow this minimum standard as well as provide the number of missing values and note totals derived from multi-time step values when providing daily or monthly totals.

\section{Conclusions}

Mesonets have developed and evolved independently, each within a unique context and operational history. This paper aims to provide recommendations and guidance that is reflective of the current operational diversity of mesonets. The authors envision that as mesonets evolve and achieve greater commonality in operational practices, there will be a subsequent need to further refine these recommendations to provide more detailed standards. Likewise, it will be important for a national organization to archive and make available the core metadata fields that have been recommended.

The authors strongly believe that strategic commitments and subsequent investments leading toward greater commonality will create synergies that will help to advance the development and delivery of weather and climate services at the local, state, regional, and national levels. Adoption of common practices among mesonets promises to produce efficiencies in operations, research and development, and customer service. Further, by providing high-quality data that are more seamlessly integrated at regional and national scales, mesonets will be better positioned to build and strengthen partnerships in the public and private sectors that will be essential to creating a viable and sustainable national mesonet.

Acknowledgments. The authors acknowledge the valuable input provided from members of the many AASC-affiliated mesonets who contributed to the recommendations detailed in this document. These experts include Adnan Akyuz, Stonie Cooper, David Dubois, David Grimsley, Pat Guinan, Beth Hall, Sean Heuser, Kevin Hyde, Sytske Kimball, Mary Knapp, Pam Knox, Jamie Lahowetz, Daniel Leathers, Cynthia Luttrell, Shawn Naylor, David Robinson, Dennis Todey, and John Travlos.

\section{REFERENCES}

Allen, R. G., L. S. Pereira, D. Raes, and M. Smith, 1998: Crop evapotranspiration: Guidelines for computing crop water requirements. FAO Irrigation and Drainage Paper 56, 300 pp., www.fao.org/docrep/X0490E/X0490E00.htm.

Alter, J. C., 1937: Shielded storage precipitation gages. Mon. Wea. Rev., 65, 262-265, https://doi.org/10.1175/1520-0493(1937) $65<262: \mathrm{SSPG}>2.0 . \mathrm{CO} ; 2$.

American Society of Agricultural and Biological Engineers, 2015:Measurement and reporting practices for automatic agricultural weather stations. ASAE Rep. EP505.1 APR2015, 20 pp., https://webstore.ansi.org/Standards/ASABE/ ASAEEP505APR2015R2019.

Anderson, C. I., and W. A. Gough, 2018: Accounting for missing data in monthly temperature series: Testing rule-of-thumb omission of months with missing values. Int. J. Climatol., 38, 4990-5002, https://doi.org/10.1002/joc.5801.

Basara, J. B., and T. M. Crawford, 2000: Improved installation procedures for deep layer soil moisture measurements. J. Atmos. Oceanic Technol., 17, 879-884, https://doi.org/ 10.1175/1520-0426(2000)017<0879:IIPFDL > 2.0.CO;2.

—, P. K. Hall Jr., A. J. Schroeder, B. G. Illston, and K. L. Nemunaitis, 2008: Diurnal cycle of the Oklahoma City urban heat island. J. Geophys. Res., 113, D20109, https://doi.org/ 10.1029/2008JD010311.

Bell, J. E., and Coauthors, 2013: U.S. Climate Reference Network soil moisture and temperature observations. J. Hydrometeor., 14, 977-988, https://doi.org/10.1175/JHM-D-12-0146.1. 
Brock, F. V., K. C. Crawford, R. L. Elliott, G. W. Cuperus, S. J. Stadler, H. L. Johnson, and M. D. Eilts, 1995: The Oklahoma Mesonet: A technical overview. J. Atmos. Oceanic Technol., 12, 5-19, https://doi.org/10.1175/1520-0426(1995)012<0005: TOMATO $>2.0 . \mathrm{CO} ; 2$.

Brook, R. R., and K. T. Spillane, 1970: On the variation of maximum wind gusts with height. J. Appl. Meteor., 9, 72-78, https://doi.org/ 10.1175/1520-0450(1970)009<0072:OTVOMW>2.0.CO;2.

Callahan, W., and J. T. Klopcic, 2011: National mesonet initiatives, end-to-end collection of metadata using international standard formats. 15th Symp. on Integrated Observing and Assimilation Systems for the Atmosphere, Oceans and Land Surface, Seattle, WA, Amer. Meteor. Soc., 1.2, https://ams.confex.com/ams/ 91Annual/webprogram/Paper184146.html.

Dingman, S. L., 1994: Physical Hydrology. Maxwell Macmillan International, $575 \mathrm{pp}$.

Duchon, C. E., and G. R. Essenberg, 2001: Comparative rainfall observations from pit and aboveground rain gauges with and without wind shields. Water Resour. Res., 37, 3253-3263, https://doi.org/10.1029/2001WR000541.

— C. Fiebrich, and D. Grimsley, 2014: Using high-speed photography to study undercatch in tipping-bucket rain gauges. J. Atmos. Oceanic Technol., 31, 1330-1336, https://doi.org/ 10.1175/JTECH-D-13-00169.1.

Environmental Protection Agency, 2000: Meteorological monitoring guidance for regulatory modeling applications. EPA Rep. EPA-454/R-99-005, 171 pp.

Fiebrich, C. A., and K. C. Crawford, 2001: The impact of unique meteorological phenomena detected by the Oklahoma Mesonet and ARS Micronet on automated quality control. Bull. Amer. Meteor. Soc., 82, 2173-2187, https://doi.org/ 10.1175/1520-0477(2001)082<2173:TIOUMP>2.3.CO;2.

—, D. L. Grimsley, R. A. McPherson, K. A. Kesler, and G. R. Essenberg, 2006: The value of routine site visits in managing and maintaining quality data from the Oklahoma Mesonet. J. Atmos. Oceanic Technol., 23, 406-416, https://doi.org/ 10.1175/JTECH1852.1.

—, C. R. Morgan, A. G. McCombs, P. K. Hall Jr., and R. A. McPherson, 2010: Quality assurance procedures for mesoscale meteorological data. J. Atmos. Oceanic Technol., 27, 15651582, https://doi.org/10.1175/2010JTECHA1433.1.

Fischer, A. P., 2011: The measurement factors in estimating snowfall derived from snow cover surfaces using acoustic snow depth sensors. J. Appl. Meteor. Climatol., 50, 681-699, https:// doi.org/10.1175/2010JAMC2408.1.

Gallo, K. P., 2005: Evaluation of temperature differences for paired stations of the U.S. Climate Reference Network. J. Climate, 18, 1629-1636, https://doi.org/10.1175/JCLI3358.1.

Haugland, M. J., 2004: Isolating microscale phenomena from mesoscale observations. 18th Conf. on Hydrology, Seattle, WA, Amer. Meteor. Soc., JP4.9, https://ams.confex.com/ams/ 84Annual/techprogram/paper_72946.htm.

Illston, B. G., and C. A. Fiebrich, 2017: Horizontal and vertical variability of observed soil temperatures. Geosci. Data J., $\mathbf{4}$, 40-46, https://doi.org/10.1002/gdj3.47.

—_, J. B. Basara, D. K. Fisher, R. Elliott, C. A. Fiebrich, K. C. Crawford, K. Humes, and E. Hunt, 2008: Mesoscale monitoring of soil moisture across a statewide network. J. Atmos. Oceanic Technol., 25, 167-182, https://doi.org/ 10.1175/2007JTECHA993.1.

Justus, C. G., and A. Mikhail, 1976: Height variation of wind speed and wind distribution statistics. Geophys. Res. Lett., 3, 261264, https://doi.org/10.1029/GL003i005p00261.
Kumamoto, M., M. Otsuka, T. Sakai, T. Hamagami, H. Kawamura, T. Aoshima, and F. Fujibe, 2013: Field experiment on the effects of a nearby asphalt road on temperature measurement. SOLA, 9, 56-59, https://doi.org/10.2151/sola.2013013.

Leeper, R. D., J. Kochendorfer, T. A. Henderson, and M. A. Palecki, 2019: Impacts of small-scale urban encroachment on air temperature observations. J. Appl. Meteor. Climatol., 58, 1369-1380, https://doi.org/10.1175/JAMCD-19-0002.1.

Lin, X., and K. G. Hubbard, 2004: Sensor and electronic biases/errors in air temperature measurements in common weather station networks. J. Atmos. Oceanic Technol., 21, 1025-1032, https://doi.org/10.1175/1520-0426(2004)021<1025: SAEEIA $>2.0 . \mathrm{CO} ; 2$.

Mahmood, R., and Coauthors, 2017: Mesonets: Mesoscale weather and climate observations for the United States. Bull. Amer. Meteor. Soc., 98, 1349-1361, https://doi.org/10.1175/BAMS-D15-00258.1.

Marshall, C. H., 2016: The National Mesonet Program. 22nd Conf. on Applied Climatology, New Orleans, LA, Amer. Meteor. Soc., 2.4, https://ams.confex.com/ams/96Annual/webprogram/ Paper290349.html.

Martinez, J. E., C. A. Fiebrich, and M. A. Shafer, 2004: The value of a quality assurance meteorologist. 14th Conf. on Applied Climatology, Seattle, WA, Amer. Meteor. Soc., 7.4, http:// ams.confex.com/ams/pdfpapers/69793.pdf.

National Oceanic and Atmospheric Administration, 1998: Automated Surface Observing System (ASOS) users guide. NOAA Rep., 74 pp., https://www.weather.gov/media/asos/ aum-toc.pdf.

_- 2018: Requirements and standards for NWS climate observations. NOAA Rep., 28 pp., https://www.nws.noaa.gov/directives/ sym/pd01013002curr.pdf.

National Research Council, 2009: Observing Weather and Climate from the Ground Up: A Nationwide Network of Networks. National Academies Press, 250 pp., https://doi.org/10.17226/ 12540.

National Weather Service, 2003: Cooperative station management. National Weather Service Instruction 10-1307, 11 pp.

__ 2019: National digital forecast database and local database description and specifications. National Weather Service Directive 10-201, 19 pp., https://www.nws.noaa.gov/ directives/.

Reges, H. W., N. Doesken, J. Turner, and N. Newman, 2016: CoCoRaHS: The evolution and accomplishments of a volunteer rain gauge network. Bull. Amer. Meteor. Soc., 97, 1831-1846, https://doi.org/10.1175/BAMS-D-14-00213.1.

Richardson, S. J., F. V. Brock, S. R. Semmer, and C. Jirak, 1999: Minimizing errors associated with multiplate radiation shields. J. Atmos. Oceanic Technol., 16, 1862-1872, https://doi.org/10.1175/1520-0426(1999)016<1862:MEAWMR> 2.0.CO;2.

Ryan, W. A., N. J. Doesken, and S. Fasssnacht, 2008: Evaluation of ultrasonic snow depth sensors for U.S. snow measurements. J. Atmos. Oceanic Technol., 25, 667-684, https://doi.org/ 10.1175/2007JTECHA947.1.

Schaefer, G. L., M. H. Cosh, and T. J. Jackson, 2007: The USDA Natural Resources Conservation Service Soil Climate Analysis Network (SCAN). J. Atmos. Oceanic Technol., 24, 2073-2077, https://doi.org/10.1175/2007JTECHA930.1.

Tanner, B. D., 1990: Automated weather stations. Remote Sens. Rev., 5, 73-98, https://doi.org/10.1080/02757259009532123. 
Taylor, B. N., and C. E. Kuyatt, 1994: Guidelines for evaluating and expressing the uncertainty of NIST measurement results. NIST Tech. Note 1297, 23 pp.

Thomas, C. K., and A. R. Smoot, 2013: An effective, economic, aspirated radiation shield for temperature observations and its spatial gradients. J. Oceanic Atmos. Tech., 30, 526-537, https://doi.org/10.1175/JTECH-D-12-00044.1.

Woll, S., 2018: The operational value of national mesonet observations. Sixth Symp. on the Weather, Water, and Climate Enterprise, Austin, TX, Amer. Meteor. Soc., 2.2, https://ams.confex.com/ams/ 98Annual/webprogram/Paper336073.html.

World Meteorological Organization, 1993: Siting and exposure of meteorological instruments. WMO Instruments and Observing Methods Rep. 55, WMO/TD 589, 48 pp.
_- 2003: Manual on the global observing system. WMO Rep. WMO-544, Vol. I, 50 pp., https://www.wmo.int/pages/prog/ www/OSY/Manual/WMO544.pdf.

- $2014 \mathrm{a}$ : Annex 1B. Siting classifications for surface observing stations on land. Guide to meteorological instruments and methods of observation, WMO Rep. WMO-8, 31-42, http://www.wmo.int/pages/prog/www/IMOP/SitingClassif/ SitingClassif.html.

_ 2014b: Guide to meteorological instruments and methods of observation. 8th ed. WMO Rep. WMO-8, 569 pp.

- 2014c: The WMO strategy for service delivery and its implementation plan. WMO Rep. WMO-1129, 130 pp.

_ 2018: Guide to climatological practices. 3rd ed. WMO Rep. WMO-100, $153 \mathrm{pp}$. 